DOI: 10.2478/romneu-2014-0006

\title{
Surgery in tumors of the lateral ventricles - last 8 years experience
}

\author{
Mugurel Radoi, Leon Danaila, Florin Stefanescu, Daniel Petrescu, \\ Ram Vakilnejad
}

Neurosurgery Clinic of the National Institute of Neurology and Neurovascular Diseases, Bucharest

\begin{abstract}
Introduction: Tumors of the lateral ventricle are rare lesions including a large variety of benign or malignant tumors. These tumors could originate in the ventricular wall or arising and expanding within the lateral ventricle from the surrounding neural structures. The purpose of this study is to discuss postoperative results and factors that affected the preference for transcallosal or transcortical approach.

Material and methods: We performed a retrospective study, lasted between 20052013, that comprised 26 consecutive patients who underwent operation for lateral ventricle tumors. The main clinical symptoms and signs were associated with the localization and size of the tumors. Cerebral computed tomography and magnetic resonance imaging were used to determine the location and expansion of each tumor. The transcortical approach was used in 17 patients and the transcallosal approach was used in 9 patients.
\end{abstract}

Results: Total tumor resection was achieved in $73 \%$ of cases (19 patients).
Most frequent histological tumor's type was glioblastoma, choroid plexus papilloma, ependymoma and meningioma. Signs of increased intracranial pressure were most dominant. One patient died because of postoperative intraventricular hemorrhage. Additional neurological deficits were seen in 3 patients and postoperative seizure occurred in three patients. One patient with preoperative hydrocephalus required ventriculoperitoneal shunting after tumor's resection. Two patients developed postoperative epidural hematoma and one required reoperation. 15 of 26 patients received postoperative radiotherapy and 6 of them received adjuvant chemotherapy. The mean duration of postoperative evaluation was 24,32 (range 5-92). Excepting the cases with subtotal resection, two patients were reoperated for recurrences.

Conclusions: The nature, size, location and vascularization of intraventricular tumors are the most important elements influencing the choice of surgical approach. Surgeons must evaluate all these factors and prefer the short and safe way to remove the tumor. 


\section{Introduction}

Tumors of the lateral ventricle are rare lesions including a large variety of benign or malignant tumors. Intraventricular tumors are more common in children than in adults, accounting for approximately 1$3 \%$ of adult brain tumors $(4,5,9)$, and till $16 \%$ of childhood and adolescent brain tumors (9). Of intraventricular brain tumors, $49 \%$ in adults are found in the lateral ventricle (9).

Tumors of the lateral ventricle originate from the ependyma and subependyma that line the ventricles, from the choroid plexus arachnoid and epithelium, or from ectopic tissue rests that have become trapped within the ventricle or its lining (2). Tumors expanding within the ventricular cavity cause symptoms and signs of obstruction of the normal cerebrospinal fluid (CSF) pathways, compression of the adjacent neural structures, or hydrocephalusinduced by overproduction of $\operatorname{CSF}(13,14,25)$.

The most frequently encountered pathologic diagnosis in tumors of the lateral ventricle, in adults, is astrocytoma, meningioma, ependymoma and choroid plexus papilloma $(5,9,13)$. Other rare intraventricular lesions are: subependymoma, subependymal giant cell astrocytoma, neurocytoma, teratoma,epidermoid tumors and metastatic carcinoma (5,11,13,20). Magnetic resonance imaging (MRI) has become the preferred modality for preoperative evaluation because it provides the best three-dimensional images of these intraventricular tumors and their relationship to surrounding structures.

Microsurgical resection is the treatment of choice for lateral ventricle tumors. The optimal approach depends on the location and size of the lesion, the size of the lateral ventricles, and the relationship of the tumor to the third ventricle. The transcortical or transcallosal routes afford the surgeon the possibility to completely remove most of these tumors. The location of the lateral ventricles makes passing through cortical structures mandatory in all approaches to these tumors (25). The transcallosal approach may decrease the risk of postoperative seizures and functional deficits $(2,6,26)$. Anterior or posterior transcallosal approaches can be safely used to excise tumors located in the ventricular body or atrium. The transcortical approach has the advantage of simplicity, and became an attractive alternative to the transcallosal approach for many tumors located in the frontal, temporal and occipital horn and atrium (19). The presence or absence of preoperative neurologic deficits also influences the surgeon's decision in selecting a particular approach $(4,6,8)$.

We presented our clinical and surgical data for a consecutive series of 26 patients with lateral ventricle tumors.

\section{Material and methods}

Between January 2005 and August 2013 in our Neurosurgical Department of the National Institute of Neurology and Neurovascular Diseases, there were 26 
consecutive patients who underwent surgery for tumors of the lateral ventricles. We performed a retrospective study that included clinical, radiological, surgical and pathological data from our recordings. We included in our series neoplasms that originate in the lateral ventricle wall (primary ventricular tumors) and neoplasms arising in the adjacent brain structures but with exophytic grow within the ventricles. Two main surgical approaches were used in tumor resection: transcortical approach (17 patients) and transcallosal approach (9 patients). We analyzed the factors that influenced the choice of surgical approach: location of the tumor within the third ventricle, expansion and size of the tumor, approaching from dominant/non-dominant hemisphere, size of ventricles, postoperative residue tumor size and postoperative complications.

The 26 patients included 14 males and 12 females. The mean age at admission was 38 years (range 17 to 69 years). There was no pediatric population in our study. The number of males and females was approximately equal in all tumor categories, excepting glioblastoma (male dominancy 3M:1F) and meningioma (female dominancy 1M:4F). The distribution of patients according to the age and sex groups is shown in Table I.

Clinical signs and symptoms depended on the location of the tumor (Table II). The symptoms and signs for tumors located in the ventricular body were high intracranial pressure syndromes, mental disturbances, motor and sensorial deficits.
For tumors located in the frontal horn neurological signs were headache, seizures, mental disturbances and high intracranial pressure syndromes. Patients with tumors located in the temporal horn or occipital horn developed mainly headache, motor and sensorial deficits, visual deficits and aphasia for the dominant hemisphere. Clinical symptoms and signs for tumors located in the atrium included high intracranial pressure signs, mental disturbances, motor and sensorial deficits.

Preoperative computed tomography (CT) and magnetic resonance imaging (MRI) images, both contrast-enhanced and unenhanced, were examined to determine the location and expansion of each tumor, appearance and specific tissue signs characteristics. The arterial supplies of the tumor, arterial and venous anatomy of the region, were studied with cerebral angiography in 7 patients. Preoperative hydrocephalus was noted in 4 patients.

\section{TABEL I}

The distribution of the patients according to the age groups and gender

\begin{tabular}{|l|l|l|l|}
\hline Age (years) & No of patients & Male & Female \\
\hline $0-11$ & 0 & 0 & 0 \\
\hline $11-20$ & 4 & 2 & 2 \\
\hline $21-30$ & 6 & 4 & 2 \\
\hline $31-40$ & 3 & 1 & 2 \\
\hline $41-50$ & 6 & 2 & 4 \\
\hline $51-60$ & 4 & 3 & 1 \\
\hline $61-70$ & 3 & 2 & 1 \\
\hline$>71$ & 0 & 0 & 0 \\
\hline Total & 26 & 14 & 12 \\
\hline
\end{tabular}


TABLE II

Signs and symptoms according to the tumor location

\begin{tabular}{|l|l|l|l|l|l|l|l|l|}
\hline $\begin{array}{l}\text { Tumor } \\
\text { location }\end{array}$ & $\begin{array}{l}\text { No of } \\
\text { patients }\end{array}$ & $\begin{array}{l}\text { High IP } \\
\text { signs }\end{array}$ & Seizures & $\begin{array}{l}\text { Mental } \\
\text { disturbances }\end{array}$ & $\begin{array}{l}\text { Motor } \\
\text { deficits }\end{array}$ & $\begin{array}{l}\text { Sensorial } \\
\text { deficits }\end{array}$ & Aphasia & $\begin{array}{l}\text { Visual } \\
\text { deficits }\end{array}$ \\
\hline $\begin{array}{l}\text { Ventricular } \\
\text { body }\end{array}$ & 8 & 7 & 1 & 2 & 4 & 5 & 0 & 0 \\
\hline Frontal horn & 4 & 2 & 2 & 2 & 1 & 0 & 1 & 0 \\
\hline $\begin{array}{l}\text { Temporal } \\
\text { horn }\end{array}$ & 5 & 3 & 2 & 0 & 2 & 2 & 2 & 1 \\
\hline $\begin{array}{l}\text { Occipital } \\
\text { horn }\end{array}$ & 3 & 3 & 0 & 0 & 1 & 1 & 0 & 1 \\
\hline Atrium & 5 & 4 & 0 & 1 & 1 & 1 & 1 & 0 \\
\hline Septum & 1 & 1 & 0 & 1 & 1 & 0 & 0 & 0 \\
\hline Total & 26 & 20 & 5 & 6 & 10 & 9 & 4 & 2 \\
\hline
\end{tabular}

Localization of the lateral ventricle tumors were the ventricular body ( 8 patients), frontal horn (4 patients), temporal horn (5 patients), occipital horn (3 patients), atrium (5 patients) and septum pellucidum (1 patient). The distribution according to the tumor's histology is presented in Table III. Most of the tumors had transependymal expansion, mainly in the frontal and temporal horn and corpus callosum. Only choroid plexus papilloma and arachnoid cysts had no transependymal expansion.

In choosing the surgical approach we took into account the location, expansion and the size of the tumor, whether it is in the dominant or non-dominant hemisphere. We used the frontal transcortical approach (5 cases), temporal transcortical approach (8 cases), parietal transcortical approach (4 cases), anterior transcallosal approach (7), and posterior transcallosal approach (2).
Results

Surgical results regarding the extent of tumor removal and approach used according to tumor origin are shown in Table IV. For tumors located in the frontal horn we used in all 4 patients the transcortical middle frontal gyrus approach (figure 1). Total excision was achieved in 2 cases. The temporal horn tumors were accessed through a cortical middle temporal gyrus (figure 2) or occipitotemporal incision. Difficulty was encountered in tumors located in dominant hemisphere due to lack of cortical stimulation and mapping. Total resection was achieved in 4 cases. For occipital horn tumors transcortical approach was used in all cases (figure 3). A superior parietal cortical incision was made in 2 cases, one of them in dominant hemisphere, and a temporooccipital cortical incision was made for removing a choroid plexus papilloma. Total excision of 
tumors was performed in all 3 cases. For tumors located in the body of the lateral ventricles, anterior transcallosal approach was used in most of the cases (figure 4 and figure 5). Only a frontal transcortical approach was used for resection of a glioblastoma. With the exception of glioblastomas, the other tumors did not exhibit transependymal extension. Subtotal resection was performed in 2 patients with glioblastoma and total resection in 6 cases. Tumors located in the atrium (figure 6) were resected through a temporal or parietal transcortical route in 3 cases, and a posterior transcallosal route was used for the excision of an arachnoid cyst. Total resection was achieved in 4 out of 5 patients. For a single patient with a small tumor located in the septum pellucidum, we achieved total resection through a posterior transcallosal approach.

\section{TABLE III}

Distribution of patients depending on tumor's histology

\begin{tabular}{|l|l|}
\hline Tumor histology & No of patients \\
\hline Glioblastoma & 4 \\
\hline Choroid plexus paplilloma & 5 \\
\hline Meningioma & 5 \\
\hline Ependymoma & 4 \\
\hline Oligodendroglioma & 2 \\
\hline Arachnoid cysts & 1 \\
\hline Anaplastic astrocytoma & 1 \\
\hline Fibrilar astrocytoma & 1 \\
\hline $\begin{array}{l}\text { Subependymal giant cell } \\
\text { atrocytoma }\end{array}$ & 1 \\
\hline Subependymoma & 1 \\
\hline Metastasis & 1 \\
\hline
\end{tabular}

\section{TABLE IV}

Type of approach and grade of resection of the tumors depending on their location

\begin{tabular}{|c|c|c|c|}
\hline \multicolumn{4}{|c|}{ FRONTAL HORN } \\
\hline Histologic type & Extension & Surgical approach & Grade of resection \\
\hline Oligodendroglioma & Frontal lobe & F transcortical & Subtotal \\
\hline Meningioma & Frontal lobe & F transcortical & Total \\
\hline Glioblastoma & Frontal lobe & F transcortical & Subtotal \\
\hline Metastasis & Frontal lobe & F transcortical & Total \\
\hline \multicolumn{4}{|c|}{ TEMPORAL HORN } \\
\hline Histologic type & Extension & Surgical approach & Grade of resection \\
\hline Meningioma (2) & Temporal lobe & $\mathrm{T}$ transcortical & Total \\
\hline Fibrilar astrocytoma & Temporal lobe & $\mathrm{T}$ transcortical & Total \\
\hline Ependimoma & Temporal lobe & $\mathrm{T}$ transcortical & Subtotal \\
\hline Choroid plexus papilloma & No & $\mathrm{T}$ transcortical & Total \\
\hline \multicolumn{4}{|c|}{ VENTRICULAR BODY } \\
\hline Histologic type & Extension & Surgical approach & Grade of resection \\
\hline Glioblastoma (2) & Corpus callosum & $\begin{array}{l}\mathrm{F} \quad \text { transcortical/Ant } \\
\text { transcallosal }\end{array}$ & Subtotal \\
\hline Ependymoma (2) & No & Ant transcallosal & Total \\
\hline
\end{tabular}




\begin{tabular}{|c|c|c|c|}
\hline $\begin{array}{l}\text { Choroid plexus papilloma } \\
\text { (2) }\end{array}$ & No & Ant transcallosal & Total \\
\hline Oligodendroglioma & No & Ant transcallosal & Total \\
\hline $\begin{array}{l}\text { Subependymal giant cell } \\
\text { astrocytoma }\end{array}$ & No & Ant transcallosal & Total \\
\hline \multicolumn{4}{|c|}{ ATRIUM } \\
\hline Histologic type & Extension & Surgical approach & Grade of resection \\
\hline Ependymoma & Parietal lobe & P transcortical & Subtotal \\
\hline Meningioma (2) & $\begin{array}{l}\text { Temporal lobe/occipital } \\
\text { lobe }\end{array}$ & $\mathrm{T}$ transcortical & Total \\
\hline Choroid plexus papilloma & No & $\mathrm{T}$ transcortical & Total \\
\hline Arachnoid cyst & No & Post transcallosal & Total \\
\hline \multicolumn{4}{|c|}{ OCCIPITAL HORN } \\
\hline Histologic type & Extension & Surgical approach & Grade of resection \\
\hline Glioblastoma & Parietal lobe & $\mathrm{P}$ transcortical & Total \\
\hline Choroid plexus papilloma & No & P transcortical & Total \\
\hline Anaplastic astrocytoma & Parietal lobe & $\mathrm{P}$ transcortical & Total \\
\hline \multicolumn{4}{|c|}{ SEPTUM PELLUCIDUM } \\
\hline Histologic type & Extension & Surgical approach & Grade of resection \\
\hline Subependymoma & No & Post transcallosal & Total \\
\hline
\end{tabular}

F,T,P transcortical - frontal, temporal, parietal transcortical approach; ant/post transcallosal - anterior or posterior transcallosal approach.

Total tumor resection was achieved in most of the benign or low-grade tumors, and subtotal resection was performed mainly in patients with malignant tumors. From 26 patients who underwent surgery, total resection was achieved in $73 \%$ (19 patients). We performed subtotal resection in 6 patients: 3 with glioblastoma, 2 with ependymoma and one with oligodendroglioma.

One patient with ependymoma died 12 days after initial surgery because of intraventricular hemorrhage. The postoperative complications are presented in Table V. Postoperative intraventricular hemorrhage was noted in 2 patients who needed immediate re-operation. Epidural postoperative hematoma needing reoperation was recorded for a patient with choroid plexus papilloma, and ventriculoperitoneal shunt application was performed for a patient with glioblastoma and no preoperative hydrocephalus. A small subdural hematoma occurred in one patient and required no treatment. Additional neurological deficits were seen in 3 patients. Postoperative seizure occurred in 2 patients with oligodendroglioma and, respectively, meningioma. No additional visual defects 
DOI: 10.2478/romneu-2014-0006

were seen.

15 out of 26 patients received postoperative radiotherapy and 6 of them received adjuvant chemotherapy. The mean duration of postoperative evaluation was 24.31 months (range 5 to 92 months). Shortest follow-up period was recorded in glioblastoma patients with 5, 8 and, respectively 11 months. Long periods of follow-up were encountered in patients with meningioma: 84 and, respectively, 92 months, and choroid plexus papilloma with 72 months of follow-up. At the end of follow-up, there were no recurrences or increased in tumor sizes in meningioma, choroid plexus papilloma, subependymal giant cell astrocytoma, subependymoma and arachnoid cyst. The maximum recurrences and increased tumor size were seen in glioblastoma. Excepting the cases with subtotal resection, 2 patients with recurrences were reoperated (ependymoma and anaplastic astrocytoma).

\section{TABLE V}

Number of postoperative complications related to the tumor's histology and initial number of patients

\begin{tabular}{|l|l|l|}
\hline Tumor type & $\begin{array}{l}\text { No of } \\
\text { patients }\end{array}$ & $\begin{array}{l}\text { Postoperative } \\
\text { complications }\end{array}$ \\
\hline Glioblastoma & 4 & $\begin{array}{l}\text { Intraventricular } \\
\text { hemorrhage and } \\
\text { reoperation (1); } \\
\text { ventriculo-peritoneal } \\
\text { application (1); additional } \\
\text { neurological deficits (2); } \\
\text { no complication (2). }\end{array}$ \\
\hline
\end{tabular}

\begin{tabular}{|l|l|l|}
\hline $\begin{array}{l}\text { Choroid plexus } \\
\text { papilloma }\end{array}$ & 5 & $\begin{array}{l}\text { Epidural hematoma and } \\
\text { reoperation (1) }\end{array}$ \\
\hline Ependymoma & 4 & $\begin{array}{l}\text { Intraventricular } \\
\text { hemorrhage and death } \\
(1) ; \text { no complication (3). }\end{array}$ \\
\hline Meningioma & 5 & $\begin{array}{l}\text { Brain edema (1); seizure } \\
(1)\end{array}$ \\
\hline Oligodendroglioma & 2 & Seizure (1) \\
\hline Arachnoid cyst & 1 & No complication \\
\hline $\begin{array}{l}\text { Anaplastic } \\
\text { astrocytoma }\end{array}$ & 1 & $\begin{array}{l}\text { Additional neurological } \\
\text { deficits (1) }\end{array}$ \\
\hline Fibrilar astrocytoma & 1 & No complication \\
\hline $\begin{array}{l}\text { Subependymal giant } \\
\text { cell astrocytoma }\end{array}$ & 1 & No complication \\
\hline Subependymoma & 1 & No complication \\
\hline Metastasis & 1 & No complication \\
\hline
\end{tabular}

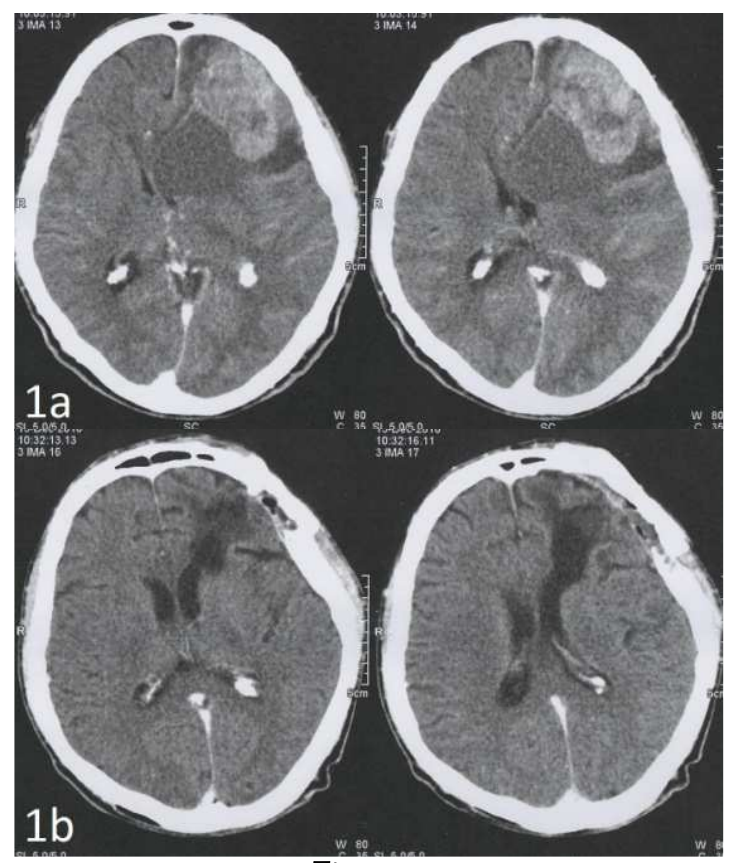

Figure 1

Metastasis developed in the frontal horn of the left lateral ventricle and expanding in ipsilateral frontal lobe; preoperative and postoperative contrast CT scan; left transcortical middle frontal gyrus approach; total resection. 


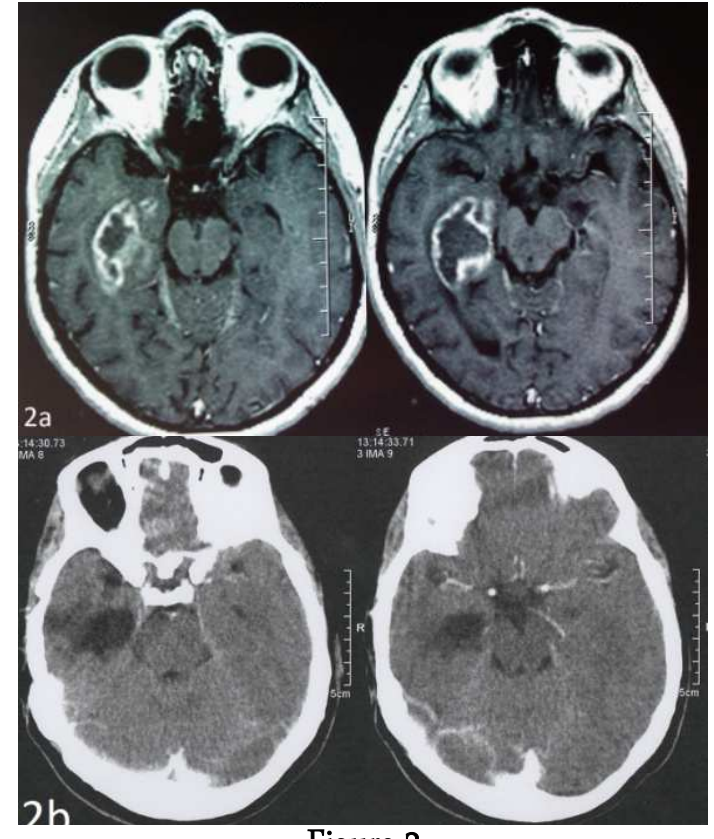

Figure 2

Fibrilar astrocytoma developed in the temporal horn of the right lateral ventricle; preoperative contrast MRI and postoperative contrast CT scan; right cortical middle temporal gyrus approach; total resection.

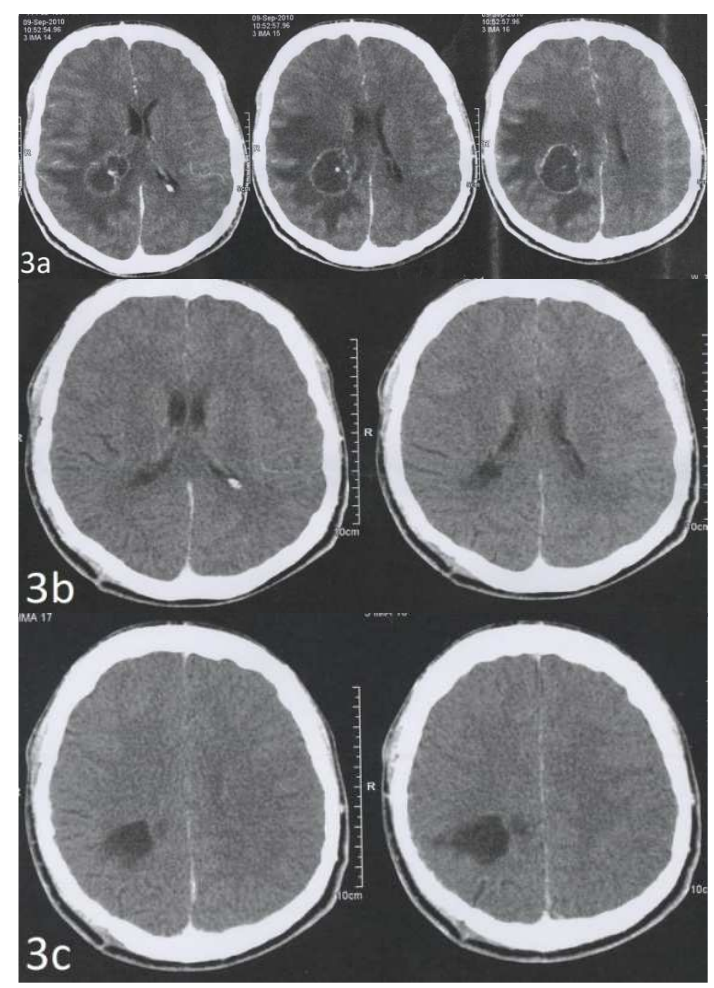

\section{Figure 3}

Anaplastic astrocytoma developed in the occipital horn of the right lateral ventricle; preoperative and 2 months postoperative CT scan; approach through a right parietal transcortical route; total resection.
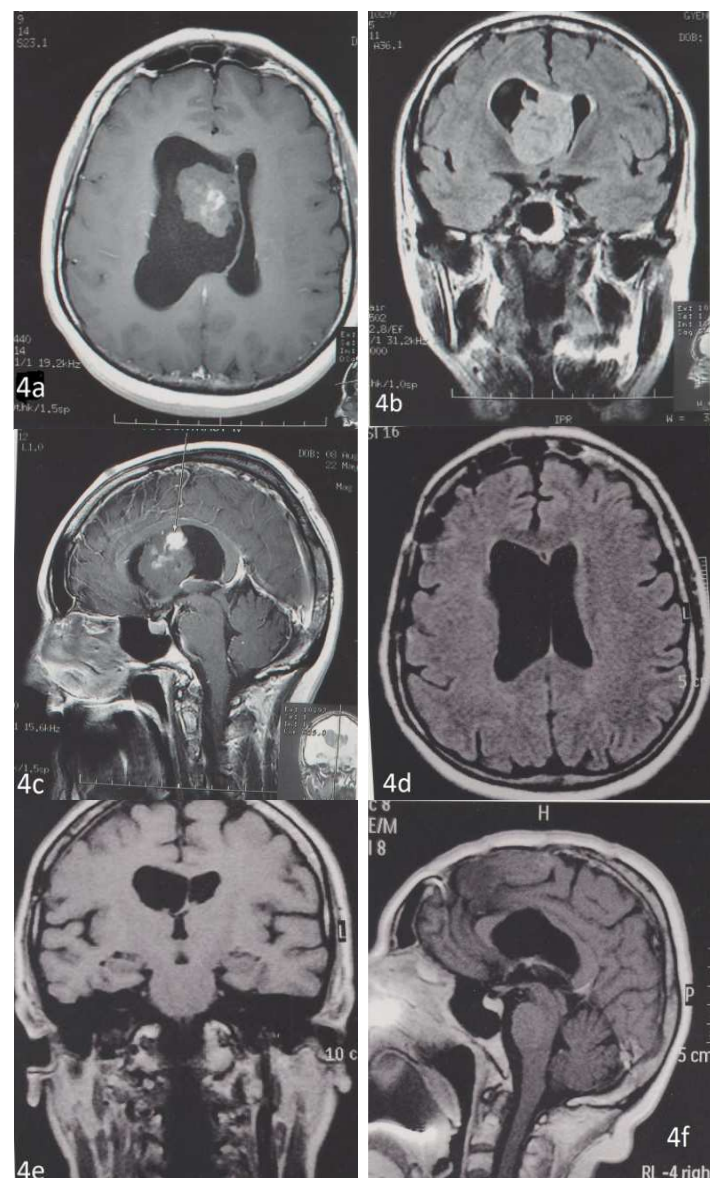

Figure 4

Subependymal giant cell astrocytoma developed in the ventricular body; preoperative and postoperative MRI; anterior transcallosal approach; total resection. 


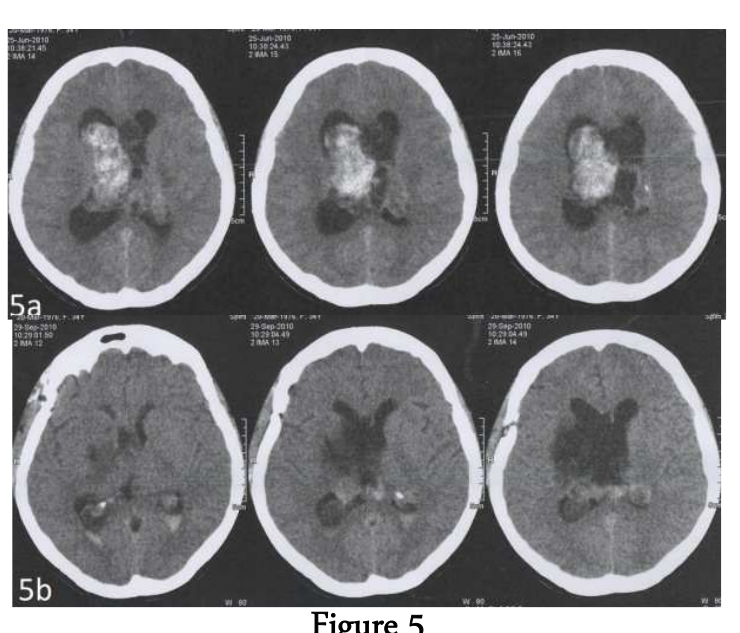

Figure 5

Ependymoma developed in the ventricular body; preoperative and postoperative (14 days after surgery) cerebral CT scan; anterior transcallosal approach; total resection.

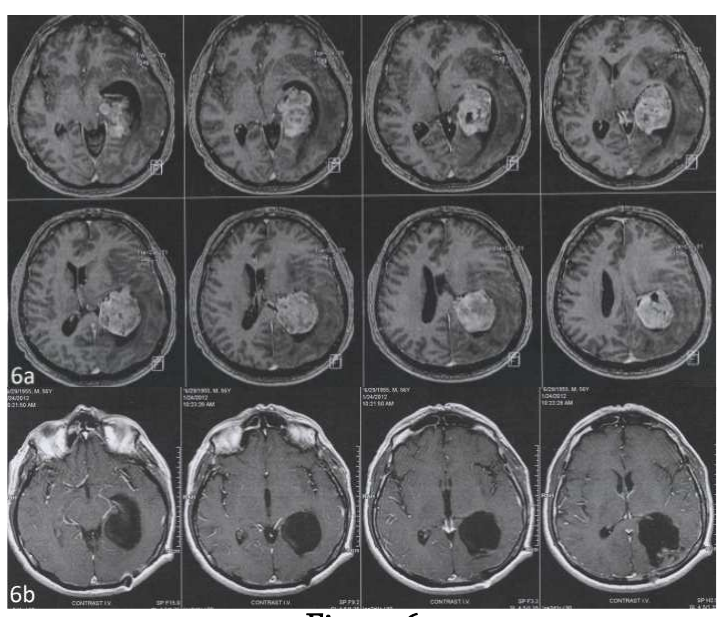

Figure 6

Meningioma developed in the atrium of the lateral ventricles; preoperative and postoperative MRI; left temporooccipital transcortical approach; total resection.

\section{Discussions}

The histopathologic diagnosis of the lateral ventricle tumors varied with the age of the patients $(5,12)$. In children, these tumors were often choroid plexus tumors, whereas in adults they tended to be gliomas $(4,7)$. In our study there were not pediatric patients. The youngest patient was 18 years old at the time of surgery. The number of males and females was approximately equal in all tumor categories, excepting glioblastoma (male dominancy 3M:1F) and meningioma (female dominancy 1M:4F).

Tumors of the lateral ventricle most often grow very large before they become clinically manifest. In order of decreasing frequency they occur in the frontal horns, ventricular body and atrium (1). In another series, the most common localizations of lateral ventricle tumors were atrium, frontal horn, ventricular body and temporal horn (10). Goklap et al (5) reported 112 lateral ventricle tumors in their study, and the most frequent sites of the tumors were the frontal horn, body and the atrium. In our series, the incidence of tumor localization within the lateral ventricles in descending order of frequency was reported as ventricular body (30.76\%), atrium (19.23\%), temporal horn (19.23\%) and frontal horn (15.38\%).

Neoplasms that originate in the ventricular wall and its lining are considered primary ventricular tumors, and, the majority of these are benign or low-grade lesions (meningioma, choroid plexus papilloma, ependymoma) $(14,16)$. Tumors that arise in the adjacent brain structures with important exophytic growth within the ventricle are considered secondary ventricle tumors with transependymal development, and they are commonly gliomas (3). In this report, the 
most frequent tumor types were meningioma (19.23\%), choroid plexus papilloma (19.23\%), glioblastoma (15.38\%) and ependymoma (15.38\%).

The best surgical approach to the tumors of the lateral ventricles is that which offers the shortest distance to the lesion with a perpendicular field of view, requires minimal retraction of the brain, avoids trajectory through functional structures and provides clear visualization of the vascular feeding branches (24). Surgical approaches to the lateral ventricles could be summarized as follow: (1) anterior approaches: anterior transcortical and anterior transcallosal, (2) posterior approaches: posterior transcortical and posterior transcallosal, (3) temporal and subtemporal transventricular approaches, inferior posterior frontotemporal (25). Due to microsurgical techniques we achieved total resection of the tumor in $73 \%$ (19 patients).

In this series, transcortical middle frontal gyrus approach was used in 5 patients for resection of tumors in the ipsilateral frontal horn or the anterior ventricular body. Most of these tumors were large and cause obstruction of the foramen of Monro. In such cases, is important to locate the foramen of Monro and avoid the damage of the fornix (25). This approach is facilitated when the lateral ventricles are enlarged. In our series, 3 out of 5 tumors operated with this approach were resected subtotally, two of them being glioblastoma multiformes.
The transcortical approach to the temporal horn is the best method to remove lesions in this area. This approach provides a short trajectory to the tumor. In the non-dominant hemisphere, this is a very acceptable route, causing minimal morbidity. We used the middle temporal gyrus approach, on the non-dominant hemisphere, to totally remove 2 tumors located in the temporal horn and 2 in the atrium. In the dominant hemisphere, the presence of the language cortex represents an important issue. In such cases, this approach requires careful dissection and retraction, refinement in techniques and the use of cortical stimulation and mapping (19). On the left hemisphere, we used this approach in 3 cases and achieved total resection with minimal postoperative aphasia.

The superior parietal approach is very suitable for reaching tumors located in the posterior part of the ventricular body and atrium, especially for large masses with a superior development (4,5). Cortical incision should be performed high enough to avoid visual field, because calcarine gyrus is adjacent to the medial wall of the atrium. Because the vascular supply to the tumor is deep, this approach did not provide access to vascular control before tumor removal. We safely performed this approach in the 4 tumors, two of them located in the dominant hemisphere. We achieve total resection of 3 tumors in the occipital horn, and a subtotal resection for an ependymoma located in the atrium. 
The transcallosal approaches to the lateral ventricle tumors was performed in 9 cases in our series. There are several advantages of these approaches over the transcortical route: reduce the risk of brain injury with appropriate brain relaxation and minimal retraction, reduce the risk of postoperative porencephalic cyst and subdural hygroma formation, low risk of postoperative seizures, low risk of functional deficits, need normal sized ventricles $(18,22)$. In the anterior transcallosal approach, the callosal section must spare the genu of the corpus callosum, especially near the rostrum and the anterior commissure anteriorly, and the posterior part of the sectioned callosum must not go beyond the interparietal commissure (23). As reported in the literature, the large tumors of the occipital horn and atrium were not suitable for posterior transcallosal resection, as the tumor itself prevented the hemispheric retraction that is required to achieve tumor removal, and for proper choroidal vessel control (17). In our series, the anterior transcallosal approach was used in 7 cases of tumors located in the ventricular body. Total tumor removal was achieved in all cases, except one patient with a glioblastoma multiforme. All tumors had small or medium size (not larger than 35 $\mathrm{mm}$.). The posterior transcallosal approach was used for resection of an arachnoid cyst from the atrium and a small ependymoma from the septum pellucidum.

In $65.5 \%$ cases we had no postoperative complications. Preoperative hydrocephalus was noted in 4 patients, but we performed shunt application in one patient who had a bifrontal glioblastoma and was operated by the anterior transcallosal approach. The number of patients requiring a shunt vary based on different factors (19). Approximately $10 \%$ to $50 \%$ of patients will ultimately required cerebrospinal fluid diversion (15).

The reported incidence of postoperative seizures after transcortical approaches varied widely from $19 \%$ to $75 \%(3,4)$. In our series, there were 5 patients who experienced postoperative seizures (19.23\%), but only two of them required prolonged antiepileptic treatment, operated using a frontal, respectively, temporal transcortical approach.

In this series, the authors reported a low mortality rate of $3.84 \%$, meaning that one out of 26 patients died secondary to an important postoperative intraventricular hemorrhage. The deaths in the last decades reported series are lower than $10 \%$ and are usually due to severe postoperative hemorrhage or pulmonary emboli $(5,6,15)$.

\section{Conclusions}

Tumors of the lateral ventricles are rare, deep-seated lesions, relatively slow growing and can became larger before causing symptoms. Because of their large size the treatment is surgical resection. The selected approach must take into account the size, location, expansion, vascularization, the critical brain structures nearby the tumor and the consequent neurologic sequelae. Our goal was 
complete resection of the tumor using microsurgical techniques, but when the tumor was malignant or attached to eloquent structures, subtotal resection was preffered. There were no significant differences in complications between the transcortical and transcallosal approaches. Finally, we can conclude that the surgeon should prefer the shortest, most familiar and the most safe way in removing a lateral ventricle tumor.

\section{Corresponding author: \\ Dr. Radoi Mugurel \\ E-mail address:muguradoi@yahoo.com \\ Tel: 0723527292}

\section{References}

1.Abosch A, McDermott WM, Wilson CB. Lateral ventricular tumors. In: Kaye $\mathrm{AH}$ and Black $\mathrm{PMcL}$, eds. Operative Neurosurgery. London-New York -Sydney: Churchill Livingstone 2000, pp. 799-814

2.Apuzzo ML, Chikoyani OK, Gott PS, Teng EL, Zee CS, Giannotta SL, Weiss MH. Transcallosal, interfornicial approaches for lesions affecting the third ventricle: surgical considerations and consequences. Neurosurgery 10:547-554, 1982

3.D'Angelo VA, Galarza M, Catapano D, Monte V, Bisceglia M, Carosi E. Lateral ventricle tumors: surgical strategies according to tumor origin and development a series of 72 cases. Neurosurgery 56 (Suppl 1): 36-45, 2005.

4.Ellenbogen RG. Transcortical surgery for lateral ventricular tumors. Neurosurg, Focus 10(6): Article 2, 2001.

5.Gokalp HZ, Yuccer N, Arasil E, Deda H, Attar A, Erdogan A, Egmen N, Kanpolat Y. Tumors of the lateral ventricle. A retrospective review of 112 cases operated upon 1970-1997. Neurosurg Rev 21:126-137, 1998.

6.Jeeves MA, Simpson DA, Gellen G. Functional consequences in the transcallosal removal of intraventricular tumors. J Neurol Neurosurg Psychiatry 42:134-142, 1979.

7.Jelinek L, Simimiotopoulos JG, Parisi JE, Kanzer M.
Lateral ventricular neoplasms of the brain: Differential diagnosis based on clinical, CT, and, MRI findings. AJR 155:365-372, 1990.

8.Kasowski H, Piepmeier JM. Transcallosal approach for tumors of the lateral and third ventricles. Neurosurg Focus 10 (6): Article (3), 2001.

9.Koos WT, Miller MH. Tumors of the ventricular system. In: Koos WT, Miller MH. Intracranial tumors of infants and children. Stuttgart: Verlag, 1970:233-253.

10.Lapras C, Deruty R, Bret PH. Tumors of the lateral ventricle. In: Symon L, eds. Advances and Technical Standards in Neurosurgery. Wien-New York: SpringerVerlag, 1984.

11.Nishito S, Fujiwara S, Tashima J, Takheshita I, Fuji K, Fukui M. Tumors of the lateral ventricular wall, especially the septum pellucidum: Clinical presentation, and variations in pathological features. Neurosurgery 27: 224-230, 1990.

12. Osborn AG. Diagnostic Neuroradiology. St Louis, Mosby; 1994: 401-528.

13.Pendl G, Ozturk E, Haselberger K. Surgery of tumors of the lateral ventricle. Acta Neurochir 116:128136, 1992.

14.Piepmeier JM, Sass KJ. Surgical management of lateral ventricular tumors. In: Paoletti P, Takakura K, Walker M, eds. Neuro-Oncology, Dordecht. Kluwer Academic Publishers, 1991: 333-335.

15.Piepmeier JM, Spencer DD, Sass K: Lateral ventricular masses. In: Apuzzo MLJ, eds. Brain Surgery: Complication Avoidance and Management. New York, Churchill Livingstone, 1993: 581-599.

16.Piempier JM, Westerveld M, Spencer DD, Sass K. surgical management of intraventricular tumors of the lateral ventricle. In: Schimdek $\mathrm{HH}$, Sweet $\mathrm{WH}$, eds. Operative Neurosurgical Techniques. Indications, Methods and Results. Philadelphia: W.B Saunders Company, 1995: 725-738.

17.Rabb CH, Apuzzo MLJ. Options in the management of ventricular masses. In: Tindall GT, Cooper PR, Barrow DL, eds. The Practice of Neurosurgery. Baltimore: Williams $\alpha$ Wilkins, 1996, 1229-1242.

18. Rhoton AL Jr. The lateral and third ventricles. Neurosurgery 51 (Suppl 1): S1-207-S1-271, 2002.

19.Secer HI, Duz B, Izci Y, Tehli O, Solmaz I, Gonul E. Tumors of the lateral ventricle: The factors that affected the preference of the surgical approach in 46 patients. Turkish Neurosurgery 2008, vol. 18, No. 4, 345-355. 20.Shen Ho Y, Plets C, Goffin J, Dom R: Hemangioblastoma of the lateral ventricle. Surg Neurol 33: 407-412, 1990. 
21.Spencer DD, Collins WF, Sass KJ. Surgical management of lateral intraventricular tumors. In: Shmidek HH, Sweet W, eds. Operative neurosurgical techniques. Orlando: Grune $\alpha$ Stratton, 1988:583.

22.Suchart W. Anterior transcallosal and transcortical approaches. In: Apuzzo MLJ, eds. Surgery of the Third Ventricle. Baltimore: Williams $\alpha$ Wilkins, 1987, pp. 303325.

23.Takafumi Nishizaki. Surgical Approaches for Lateral Ventricular Trigone Meningiomas. In: Monleon D, eds. Meningiomas - Management and Surgery. ISBN 978953-51-0175-8., 2012.
24.Tew JMJr, Lewis AL, Reichert KW. Management strategies and surgical techniques for deep-seated supratentorial arteriovenous malformations. Neurosurgery 36:1065-1072, 1995.

25.Timurkaynak E, Rhoton MD Jr, Barry M. Microsurgical anatomy and operative approaches to the lateral ventricles. Neurosurgery 19: 685-723, 1986.

26.Winston KR, Cavazzuti V, Arkins T: Absence of neurological and behavioral abnormalities after anterior transcallosal operation for third ventricular lesions. Neurosurgery 4:386-393, 1979. 